http://jmscr.igmpublication.org/home/ ISSN (e)-2347-176x ISSN (p) 2455-0450 crossref DOI: https://dx.doi.org/10.18535/jmscr/v7i7.65

\title{
Prevalence, Severity and Morphological Analysis of Anemia among Pregnant Women in a Tertiary Care Medical College and Hospital, Pondicherry
}

\author{
Authors \\ Sivaganesh@ Porko. G ${ }^{1^{*}}$, Priyadharishini $\mathbf{J}^{2}$ \\ ${ }^{1,2}$ Assistant Professor, Department of Pathology, Sri Lakshmi Narayana Institute of Medical Sciences, \\ Pondicherry, India \\ *Corresponding Author \\ Dr Sivaganesh @ Porko. G \\ Assistant Professor, Department of Pathology, Sri Lakshmi Narayana Institute of Medical Sciences, \\ Pondicherry, India - 605009
}

\begin{abstract}
Background: Anemia is one of the major health problems affecting both the developed as well as the developing countries. The prevalence of anemia among pregnant women in developing countries is about $51 \%$ according to World Health Organisation statistics. In India, National Family Health Survey -2 in 1998 to 99 shows that 54\% of women in rural and 46\% women in urban areas are anemics. Iron deficiency anemia (IDA) is the commonest type of anemia in pregnancy.

Objectives: The aim of the present study was to assess the prevalence, severity and Morphological analysis of anemia among pregnant women with emphasis on the early diagnosis and management

Material \& Methods: This was a retrospective, longitudinal cross sectional study conducted on all the pregnant women who attended the centre for ANC checkup for the first time at Sri Lakshmi Narayana Institute of Medical Science, Pondicherry from January 2018 to December 2018. The sample were analysed for the complete blood count including Hemoglobin concentration and RBC indices (MCV,MCH, $M C H C)$ by automated Horiba analyser and Leishman stained peripheral smear of the blood sample were done for the morphological analysis.

Results: Among the 320 pregnant women studied, the prevalence of anemia was found to be $60 \%$. Out of these had 25\% mild anemia, 30\% had moderate anemia, $5 \%$ had severe anemia according to WHO classification of anemia. Microcytic hypochromic anemia was found to be the most common morphological type o anemia (73\%)

Conclusions: The high prevalence of anemia (60\%) indicates strict implementation of National Nutrition Anemia prophylaxis programme. This study emphasis on the prevalence and severity of anemia in pregnancy and their implications on the maternal and fetal outcome.

Keywords: Anemia, Pregnancy, severity, WHO, morphology, hemoglobin.
\end{abstract}

\section{Introduction}

According to the World Health Organization (WHO, 1972) $)^{1}$ Anemia is defined as, "a condition in which the hemoglobin concentration in the blood is below a defined level, resulting in a reduced oxygen carrying capacity of red blood 
cells.". Anemia is a major public health problem affecting both the developed as well as the developing countries. According to World Health Organization, prevalence of anaemia among pregnant women in developed countries is about $14 \%$, whereas it is still as high as $51 \%$ in the developing world ${ }^{2}$. In India the prevalence of anaemia among pregnant women is about 65$75 \%{ }^{3,4,5}$

Normal levels of hemoglobin ranges from 13.5$17.2 \mathrm{~g} / \mathrm{dl}$ in men and $12.0-15.0 \mathrm{~g} / \mathrm{dl}$ in women. Anemia in pregnancy is as a hemoglobin concentration below $11 \mathrm{~g} / \mathrm{dl}$ defined by the World Health Organization (WHO) ${ }^{6}$. Amongst several causes of anemia in pregnancy, Iron Deficiency Anemia (IDA) is the most prevalent. One of the common causes of anemia in pregnancy is Iron Deficiency Anemia (IDA). Other risk factors which are associated with maternal anemia are Malnutrition, unhealthy lifestyle, hemoglobinopathies.

Maternal anemia leads to many adverse effects on the fetuses fetal complications such as low birth weight, preterm deliveries, developmental anomalies and even neonatal death are some of them.

Prevention and management of maternal anemia is crucial to prevent morbidity and mortality of the fetus. There are four approaches towards prevention of anemia in pregnancy. These include dietary changes to increase the iron levels, iron supplementation, food fortification and other general public health measures ${ }^{7}$.

\section{Objectives}

1) To study the prevalence of anemia among pregnant women.

2) To study the severity and Morphological analysis of anemia among pregnant women

\section{Materials}

The Cross sectional study was conducted on the pregnant women attending in the Anti Natal Clinic at Sri Lakshmi Narayana Institute of Medical
Science, Pondicherry from January 2018 to December 2018. A total of 320 pregnant women blood samples were analysed.

\section{Methods}

The blood sample was analysed for Complete blood count including Hemoglobin concentration and $\mathrm{RBC}$ indices (MCV, MCH, MCHC) by automated Horiba analyser. Leishman stained peripheral smear of the blood sample were analysed for the morphological confirmation. Anemia was defined as Hemoglobin $<11 \mathrm{gm} / \mathrm{dl}$ in pregnant women and Hemoglobin $<12 \mathrm{gm} / \mathrm{dl}$ for non-pregnant women. WHO divides anemia in pregnancy into mild anemia (haemoglobin 10$10.9 \mathrm{~g} / \mathrm{dl}$ ), moderate anemia (haemoglobin 7.0-9.9 $\mathrm{g} / \mathrm{dl}$ ) and severe anemia (haemoglobin $<7 \mathrm{~g} / \mathrm{dL}$ ).

\section{Results}

Among the 320 pregnant women studied, 192 were found to anemic i.e. Hemoglobin $<11 \mathrm{~g} / \mathrm{dl}$. The prevalence of anemia was found to be $60 \%$ [Fig 1]. Most of the anemic women had moderate anemia i.e Hemoglobin 7-8.9g/dl (29\%) followed by women with mild anemia i.e Hemoglobin 9$10.9 \mathrm{~g} / \mathrm{dl}(25 \%)$ [Table 1]. Morphological analysis revealed that Microcytic hypochromic anemia was the predominant type of anemia among pregnant women $(73 \%)$ [Table 2]. The most common age group affected was 20-30 years [Table 3].

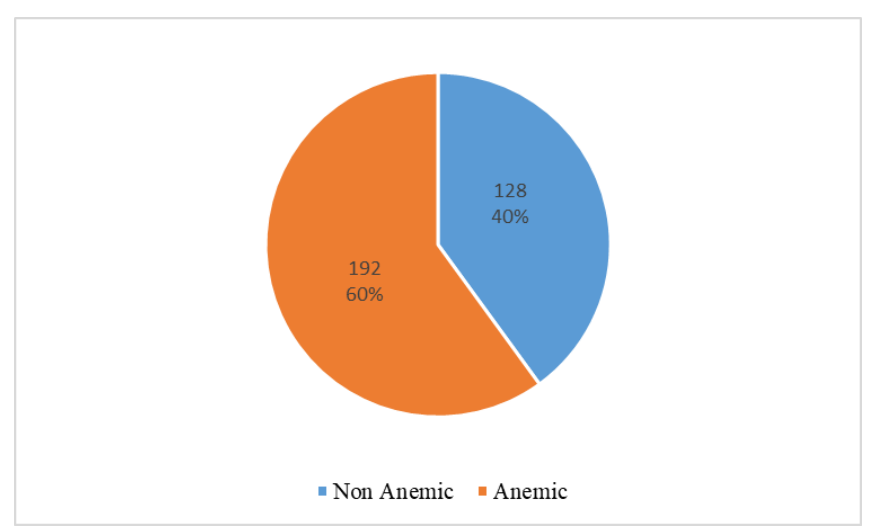

Figure 1: Prevalence of anemia among pregnant women. 
Table 1: Severity of anemia among pregnant women.

\begin{tabular}{|l|c|c|}
\hline Type & $\begin{array}{c}\text { Total } \\
\text { Number }\end{array}$ & Percentage \\
\hline Non Anemic (>11gm\%) & 128 & $41 \%$ \\
\hline Mild Anemia (9-10.9 gm\%) & 77 & $25 \%$ \\
\hline Moderate Anemia (7-8.9 gm\%) & 90 & $30 \%$ \\
\hline Severe Anemia (<7 gm\%) & 25 & $5 \%$ \\
\hline
\end{tabular}

Table 2: Morphological Analysis of Anemia

\begin{tabular}{|l|c|}
\hline $\begin{array}{l}\text { Morphological patterns of } \\
\text { anemia }\end{array}$ & Frequency (\%) \\
\hline Microcytic Hypochromic & $140(73 \%)$ \\
\hline Normocytic Normochromic & $34(18 \%)$ \\
\hline Macrocytic anemia & $18(9 \%)$ \\
\hline
\end{tabular}

Table 3: Age-wise distribution of anemic pregnant women

\begin{tabular}{|l|c|c|}
\hline Age (in years) & Total Number (\%) & Anemic \\
\hline$<20$ & $16(5 \%)$ & $4(2 \%)$ \\
\hline $20-30$ & $218(79 \%)$ & $145(75.5 \%)$ \\
\hline $30-40$ & $82(25 \%)$ & $40(21 \%)$ \\
\hline$>40$ & $4(1 \%)$ & $3(1.5 \%)$ \\
\hline
\end{tabular}

\section{Discussion}

Anemia is one of the most common nutritional deficiencies in the world. The prevalence of anemia in our study was $60 \%$ concordant with study by Srilatha et $\mathrm{al}^{8}(59.9 \%)$ and Rajamouli et $\mathrm{al}^{13}(58.36 \%)$, slightly lower compared to study by Cheema et $\mathrm{al}^{9}(65.6 \%)$ and Singh et $\mathrm{al}^{10}(65.5 \%)$ and prevalence was higher compared to the study conducted by Vanamala et al $(48.3 \%)^{11}$. In India, National Family Health Survey -2 in 1998 to 99 shows that $54 \%$ of women in rural and $46 \%$ women in urban are anaemic ${ }^{12}$

In the present study, Out of $60 \%$ of anemic women, women with mild anemia was $25 \%$, moderate anemia was $30 \%$ and severe anemia was $6 \%$ concordant with study by Srilatha et al ${ }^{8}$. In a study by Cheema et $\mathrm{al}^{9}$, mild anemia was observed in $60 \%$ of the cases, moderate in $30.4 \%$ and severe anemia in $9.6 \%$.

Most of the patients in this study were between 20-30 years of age and hence this was the most common age group who were anemic concordant with study by Vanamala et $\mathrm{al}^{11}$ and Rajamouli et $\mathrm{al}^{13}$. However, in a study by Cheema et $\mathrm{al}^{9}$, the age group between 35-49 years were more affected by this condition.
Morphological analysis and RBC indices (MCV, $\mathrm{MCH}, \mathrm{MCHC} \& \mathrm{RDW})$ revealed microcytic hypochromic anemia was the most common morphological type of anemia (73\%) in pregnant women which is in concordant with study by JB Sharma $^{14}$. The causes of microcytic hypochromic anemia are iron deficiency anemia (IDA), thalassemia and anemia of chronic diseases ${ }^{15}$.The main cause of microcytic hypochromic anemia is an iron deficiency

\section{Conclusion}

Anaemia poses a serious health threat for pregnant women and her child in developing countries like India. This study was done to emphasis on the prevalence and severity of the anemia in and around Agaram Village, Pondicherry. Nutritious diet, medication and an effective health programme is important to reduce the prevalence of anemia and thereby the morbidity and mortality associated with it.

Funding: No funding sources

Conflict of interest: None declared

\section{References}

1. Nutritional anaemias. Report of a WHO group of experts. World Health Organ Tech Rep Ser. 1972;503:1-29.

2. Mayer EM, Tegman A. Prevalence of anaemia in the World. World Health Organ Qlty. 1998;38:302-16.

3. Kalaivani K. Prevalence and consequences of anemia in pregnancy. Indian J Med Res. 2009;130:627-33.

4. Kumar V, Abbas AK, Fausto N, Aster J. Robbins and Cotran pathological basis of diseases. 8th ed. PA Saunders/Elsevier; 2010:640-1.

5. Lee AI, Okam MM. Anemia in pregnancy. Hematol Oncol Clin North Am. 2011;25(2):241-59. 2. De Mayor EM, Tegman A, Prevalence of Anaemia in the world, world Health Organisation 1998;38:302-16. 
6. WHO. Iron Deficiency Anaemia: Assessment, Prevention and Control. World Health Organisation, Geneva;2001.

7. Milman N. Prepartum aneamia. prevention and treatment. Annal Hematol. 2008 Dec 1;87(12):949-59.

8. Srilatha J. Int J Reprod Contracept Obstet Gynecol. 2017 Nov;6(11):4886-4889

9. Cheema HK, Bajwa BS, Kaur K, Joshi H. Prevalence and possible risk factors of anaemia in different trimesters of pregnancy. IJCMR. 2016;3(4):1194-7.

10. Singh AB, Kandpal SD, Chandra R, Srivastava VK, Negi KS. Anemia amongst pregnant and lactating women in district Dehradun. Indian $\mathrm{J}$ Prev Soc Med. 2009;1:19-22.

11. Vanamala VG et al. Int J Reprod Contracept Obstet Gynecol. 2018 Feb;7(2):462-466

12. Kennedy E, Dietary reforms intakes; development and uses for assessment of micronutrient status of women- a global prospective. Am J Clin Nutr. 2005;81:1194-S7S.

13. Rajamouli J, Ravinder A et al ,Study on prevalence of anemia among pregnant women attending antenatal clinic at rural health training centre (RHTC) and chalmeda anand rao institute of medical sciences teaching hospital, karimnagar, Telangana, India. International Journal of Contemporary Medical Research 2016;3(8):2388-2391

14. J.B.Sharma, Meenakshi Shankar: Anemia in Pregnancy. JIMSA October - December 2010 Vol. 23 No. 4

15. Guyatt GH, Oxman AD, Ali M, Willan A, McIlroy W, Patterson C. Laboratory diagnosis of iron-deficiency anemia: An overview. J Gen Intern Med 1992;7:14553. 